\title{
A Cross-Sectional Study of Cannabidiol Users
}

\author{
Jamie Corroon ${ }^{1,2}$ and Joy A. Phillips ${ }^{3}$
}

\begin{abstract}
Introduction: Preclinical and clinical studies suggest that cannabidiol (CBD) found in Cannabis spp. has broad therapeutic value. CBD products can currently be purchased online, over the counter and at Cannabis-specific dispensaries throughout most of the country, despite the fact that CBD is generally deemed a Schedule I controlled substance by the U.S. Drug Enforcement Administration and renounced as a dietary supplement ingredient by the U.S. Food and Drug Administration. Consumer demand for CBD is high and growing, but few studies have examined the reasons for increasing CBD use.

Materials and Methods: A self-selected convenience sample $(n=2409)$ was recruited via an online survey designed to characterize whom, how, and why individuals are currently using CBD. The anonymous questionnaire was accessed from October 25, 2017 to January 25, 2018. Participants were recruited through social media. Results: Almost $62 \%$ of CBD users reported using CBD to treat a medical condition. The top three medical conditions were pain, anxiety, and depression. Almost 36\% of respondents reported that CBD treats their medical condition(s) "very well by itself," while only $4.3 \%$ reported "not very well." One out of every three users reported a nonserious adverse effect. The odds of using CBD to treat a medical condition were 1.44 (95\% confidence interval, 1.16-1.79) times greater among nonregular users of Cannabis than among regular users.

Conclusion: Consumers are using CBD as a specific therapy for multiple diverse medical conditions - particularly pain, anxiety, depression, and sleep disorders. These data provide a compelling rationale for further research to better understand the therapeutic potential of CBD.
\end{abstract}

Keywords: cannabis; cannabidiol; CBD; marijuana; pain; anxiety

\section{Introduction}

Cannabidiol (CBD) is one of more than a hundred cannabinoids found in Cannabis sativa $\mathrm{L}$ (Cannabis spp. or Cannabis), a plant more well known colloquially as marijuana and hemp. CBD is typically the second most abundant cannabinoid found in Cannabis after tetrahydrocannabinol (THC). ${ }^{1}$ CBD was first isolated in 1940 and characterized structurally in $1963 .^{2,3}$

CBD is well tolerated in humans and maintains a good safety profile. ${ }^{4,5}$ Neither abuse nor dependence has been demonstrated. ${ }^{5}$ In preclinical studies, CBD shows potential therapeutic efficacy against a diverse assortment of medical conditions. These include sei- zure disorders, psychotic symptoms, anxiety, depression, inflammation, cancer, cardiovascular diseases, neurodegeneration, symptoms of multiple sclerosis, and chronic pain, either used alone or when coadministered with THC. ${ }^{5-20}$

In October of 2017, a New Drug Application was submitted to the U.S. Food and Drug Administration (FDA) to seek approval of CBD isolated from marijuana for the treatment of two pediatric seizure disorders. Approval was granted in June, 2018, making Epidiolex (cannabidiol) the first plant-derived Cannabis compound approved as a drug by the FDA. Availability of Epidiolex is pending Drug Enforcement Administration (DEA)

\footnotetext{
${ }^{1}$ The Center for Medical Cannabis Education, Del Mar, California.

${ }^{2}$ Helfgott Research Institute, National University of Natural Medicine (NUNM), Portland, Oregon.

${ }^{3}$ Donald P. Shiley BioScience Center, San Diego State University, San Diego, California.

*Address correspondence to: Jamie Corroon, ND, MPH, The Center for Medical Cannabis Education, 1155 Camino Del Mar, \#187, Del Mar, CA 92014, E-mail: jamie@corroon.com

() Jamie Corroon and Joy A. Phillips 2018; Published by Mary Ann Liebert, Inc. This Open Access article is distributed under the terms of the Creative Commons License (http://creativecommons.org/licenses/by/4.0), which permits unrestricted use, distribution, and reproduction in any medium, provided the original work is properly cited.
} 
rescheduling of cannabidiol, which is expected to occur within 90 days. ${ }^{21-23}$ Sativex (nabiximols), a combination drug with equal parts $\mathrm{CBD}$ and THC extracted from marijuana, is currently approved to treat spasticity due to multiple sclerosis in $>30$ countries worldwide but is not approved in the United States. ${ }^{17,21}$

The worldwide regulatory status of CBD is complex and constantly changing. ${ }^{5}$ While $\mathrm{CBD}$ is legal in many countries as a component of prescription Sativex (nabiximols), it may be simultaneously illegal as a component of a nonapproved Cannabis extract containing $>0.2 \%$ (particularly in European countries) or $0.3 \%$ THC. In Europe, individual European Union Member States currently determine the legality of CBD within their borders. Most allow prescription CBD products, as do Australia and New Zealand. ${ }^{5,24}$ Canada became the second nation in the world to legalize Cannabis for recreational use in June 2018. ${ }^{25}$ The World Health Organization's Expert Committee on Drug Dependence recommended that $\mathrm{CBD}$ should not be controlled by Schedule I of the 1961 UN Single Convention on Narcotic Drugs. ${ }^{5}$ Their comprehensive report is expected this year.

In the United States, until such time as it is rescheduled, CBD from marijuana is deemed by the DEA to fall within the purview of the "marihuana extract rule" (Rule). A dispute over the scope of the Rule was litigated in federal court. The Court found that the Rule applies to extracts of marijuana but that the industrial hemp provisions of the 2014 Farm Act (i.e., "The 2014 Farm Bill") preempt the Controlled Substances Act (CSA), which the DEA enforces. ${ }^{26}$ Thus, hemp cultivated in compliance with the Farm Bill is not a controlled substance. The Court did not address the issue of CBD directly, however, and left open the issue of the legal status of CBD derived from industrial hemp, from imported "nonpsychoactive hemp" or from parts of the Cannabis sativa plant excluded from the legal definition of marijuana in the Controlled Substances Act of 1970. ${ }^{27-35}$ Despite conflicting legal interpretations, and DEA prohibition, hemp-derived CBD products can currently be purchased as dietary supplements both online and over the counter throughout most of the country. To complicate matters further, the FDA does not recognize CBD as a dietary supplement ingredient because of its status as an Investigational New Drug. ${ }^{36}$

This regulatory confusion has not deterred consumers from exploring the purported benefits of CBD. Retail sales of hemp-derived CBD products in the United
States reached $\$ 170$ million in 2016 , and are projected to grow at a $55 \%$ compound annual growth rate over the next 5 years to reach $>\$ 1$ billion. These estimates do not include marijuana-derived $\mathrm{CBD} .{ }^{37}$ Although Cannabis users have been extensively studied data characterizing the individual use of CBD are scarce. The goal of this study was to collect survey data to elucidate how, and why, individuals are using CBD.

\section{Methods}

Survey

The study protocol was submitted electronically to the Institutional Review Board (IRB) of San Diego State University. Given the voluntary nature of the survey, and the lack of identifying information, the electronic approval process determined that no IRB approval was necessary.

We developed a novel questionnaire to assess broad characteristics of self-described CBD users and underlying reasons for, and methods of, $\mathrm{CBD}$ use. The survey consisted of structured questions answered by either yes/no or multiple-choice responses. Questions focused on several key domains: sociodemographics; reasons for use; duration and frequency of use; method of administration; perceived clinical efficacy; and adverse effects. Study data were collected and managed using Qualtrics ${ }^{\circledR}$ Survey Software, a secure tool allowing participants to directly enter responses anonymously.

Subjects were a self-selected convenience sample who accessed the online survey from October 25, 2017 to January 25, 2018. Recruitment strategies included promotion on survey-specific Web pages on Facebook, LinkedIn, and ResearchGate. CBD product manufacturers and herbal vaporizer manufacturers assisted in recruitment by promoting links to the survey on their Facebook pages and/or via email to their customers. The only inclusion criterion was current or prior use of CBD. Respondents could skip any question(s) they did not wish to answer.

\section{Data analyses}

Descriptive statistics including simple proportions were used to describe demographics, usage characteristics, medical conditions, perceived efficacy, side effects, and other CBD use preferences. Data analyses were conducted using SAS University Edition (SAS 9.4; SAS Institute Inc., Cary, NC). Univariate and bivariate comparisons were conducted using PROC FREQ and chi-square tests. Odds ratios (ORs) were used to estimate strength of association using PROC LOGISTIC. 
Statistical significance was assessed using $\alpha=0.05$. Figures were produced using DeltaGraph version 4.5 for Mac.

\section{Results}

Demographics

A total of 2490 responses were collected. Eighty-one respondents were excluded from the analysis for failure to answer the first question regarding stated use of CBD, leaving 2409 respondents included in the final study population. The sample was balanced in terms of gender (female: 50.87\%; male: $47.40 \%$ ) with most respondents reporting ages between 55 and 74 years (39.97\%). Most were either graduates of, or currently enrolled in, college or a postgraduate program $(71.22 \%)$. The vast majority resided in the United States (91.23\%). Respondents from all 50 U.S. states were represented in the survey with the majority residing in California $(n=412$, $21.90 \%$; Table 1 ). In addition, there were survey respondents from 23 other countries. Regular Cannabis use was reported by $55.17 \%$ of respondents.

\section{Stated use: medical versus general health}

and well-being

More than $60 \%(61.56 \%)$ reported using CBD to treat a medical condition(s) (Table 1). The odds of using CBD to treat a medical condition were 1.65 (95\% confidence interval [CI], 1.39-1.97) times greater among women than among men, higher with age, and roughly equal among residents and nonresidents of the United States (OR, 1.06; 95\% CI, 0.9-2.5; Table 2). Respondents $<18$ years of age were subsequently assessed as an independent category despite the small number of observations $(n=25)$ and wide CI (OR, 18.72; 95\% CI, 4.20-83.39, compared with those between 18 and 24 years of age. Data not included in Table 2). This additional analysis was based on the established use of CBD to treat pediatric seizure disorders ${ }^{6,7,16}$ and the percentage of respondents in that age category reporting using CBD to treat a medical condition $(n=23 ; 92 \%)$.

The odds of using CBD to treat a medical condition were 1.44 (95\% CI, 1.16-1.79) times greater among nonregular users of Cannabis when compared with regular users.

\section{Medical conditions}

There were 1483 respondents who reported using CBD to treat at least one medical condition. A minimum of 3963 medical conditions were reported. This represents an average of more than two and a half (mean: 2.67) different medical conditions per respondent.
Table 1. Sociodemographic and Other Characteristics of Survey Respondents ( $n=2409$ )

\begin{tabular}{|c|c|}
\hline & $n(\%)$ \\
\hline \multicolumn{2}{|l|}{ Gender } \\
\hline Male & $1013(47.40)$ \\
\hline Female & $1087(50.87)$ \\
\hline Decline to state & $37(1.73)$ \\
\hline Missing & 272 \\
\hline \multicolumn{2}{|l|}{ Age (years) } \\
\hline$\leq 24$ & $138(6.33)$ \\
\hline $25-34$ & $292(13.40)$ \\
\hline $35-44$ & $400(18.36)$ \\
\hline $45-54$ & $404(18.54)$ \\
\hline $55-64$ & $532(24.41)$ \\
\hline $65-74$ & $339(15.56)$ \\
\hline$\geq 75$ & $74(3.40)$ \\
\hline Missing & 230 \\
\hline \multicolumn{2}{|l|}{ Education } \\
\hline Primary/middle school & $22(1.01)$ \\
\hline High school/GED & $503(23.13)$ \\
\hline College & $1138(52.32)$ \\
\hline Postgraduate & $411(18.90)$ \\
\hline Other & $101(4.64)$ \\
\hline Missing & 234 \\
\hline \multicolumn{2}{|l|}{ Geography } \\
\hline United States & 1987 (91.23) \\
\hline Canada/Mexico & $103(4.73)$ \\
\hline Other & $88(4.04)$ \\
\hline Missing & 231 \\
\hline \multicolumn{2}{|l|}{ Geography-U.S. states (top 5) } \\
\hline California & $412(21.90)$ \\
\hline Texas & $93(4.94)$ \\
\hline Oregon & $83(4.41)$ \\
\hline Florida & $79(4.20)$ \\
\hline Colorado & $76(4.04)$ \\
\hline Missing & 528 \\
\hline \multicolumn{2}{|l|}{ Cannabis use } \\
\hline Regular & 1189 (55.17) \\
\hline Nonregular & $966(44.83)$ \\
\hline Missing & 254 \\
\hline \multicolumn{2}{|l|}{ CBD use } \\
\hline General health and well-being & $926(38.44)$ \\
\hline Medical condition & $1483(61.56)$ \\
\hline Missing & 0 \\
\hline
\end{tabular}

CBD, cannabidiol; GED, General Educational Development.

In order of frequency, the top three medical conditions reported were chronic pain, arthritis/joint pain, and anxiety (Fig. 1).

Respondents selected "Other" 362 times. The most common "Other" conditions reported were neuropathy $(n=48)$, autoimmune conditions $(n=38)$, and fibromyalgia $(n=37)$.

\section{Methods of administration}

A total of 4135 methods of administration were reported by 2200 respondents. This represents an average of almost two (mean: 1.88) different methods of administration per respondent. Overall, the most common method reported was the administration of CBD in a sublingual 
Table 2. Odds of Using Cannabidiol for a Medical Condition by Sociodemographic and Other Characteristics $(n=2409)$

\begin{tabular}{|c|c|c|c|}
\hline & $\begin{array}{l}\text { General health and well-being, }(n=926) \\
n(\%)\end{array}$ & $\begin{array}{l}\text { Medical condition, }(n=1483) \\
n(\%)\end{array}$ & OR $(95 \% \mathrm{Cl})$ \\
\hline \multicolumn{4}{|l|}{ Gender*** } \\
\hline Male & $454(44.82)$ & $559(55.18)$ & 1.00 (reference) \\
\hline Female & $358(32.93)$ & $729(67.07)$ & $1.65(1.39-1.97)$ \\
\hline Decline to state & $12(32.43)$ & $25(67.57)$ & $1.69(0.84-3.41)$ \\
\hline Missing & 102 & 170 & \\
\hline \multicolumn{4}{|l|}{ Age $(\text { years })^{* * *}$} \\
\hline$\leq 24$ & $72(52.17)$ & $66(47.83)$ & 1.00 (reference) \\
\hline $25-34$ & $153(52.40)$ & $139(47.60)$ & $0.99(0.66-1.49)$ \\
\hline $35-44$ & $170(42.50)$ & $230(57.50)$ & $1.48(1.00-2.18)$ \\
\hline $45-54$ & $150(37.13)$ & $254(62.87)$ & $1.85(1.30-2.73)$ \\
\hline $55-64$ & $180(33.83)$ & $352(66.17)$ & $2.13(1.50-3.12)$ \\
\hline $65-74$ & $98(28.91)$ & $241(71.09)$ & $2.68(1.80-4.04)$ \\
\hline$\geq 75$ & $19(25.68)$ & $55(74.32)$ & $3.16(1.70-5.86)$ \\
\hline Missing & 84 & 146 & \\
\hline \multicolumn{4}{|l|}{ Education $^{* * *}$} \\
\hline College & $478(42.00)$ & $660(58.00)$ & 1.00 (reference) \\
\hline Primary/middle school & $1(4.55)$ & $21(95.45)$ & $15.18(2.04-113.09)$ \\
\hline High school/GED & $172(34.19)$ & $331(65.81)$ & $1.39(1.12-1.73)$ \\
\hline Postgraduate & $153(37.23)$ & $258(62.77)$ & $1.22(0.97-1.54)$ \\
\hline Other & $34(33.66)$ & $67(66.34)$ & $1.43(0.93-2.19)$ \\
\hline Missing & 88 & 146 & \\
\hline \multicolumn{4}{|l|}{ Geography } \\
\hline United States & $763(38.40)$ & $1224(61.60)$ & 1.00 (reference) \\
\hline Canada/Mexico/other & 76 (39.79) & $115(60.21)$ & $1.06(0.78-1.44)$ \\
\hline Missing & 87 & 144 & \\
\hline \multicolumn{4}{|l|}{ Cannabis use $\mathrm{e}^{* * * *}$} \\
\hline Regular & $509(42.81)$ & $680(57.19)$ & 1.00 (reference) \\
\hline Nonregular & $320(33.13)$ & $646(66.87)$ & $1.44(1.16-1.79)$ \\
\hline Missing & 97 & 157 & \\
\hline
\end{tabular}

*** $p<0.001$.

$\mathrm{Cl}$, confidence interval; OR, odds ratio.

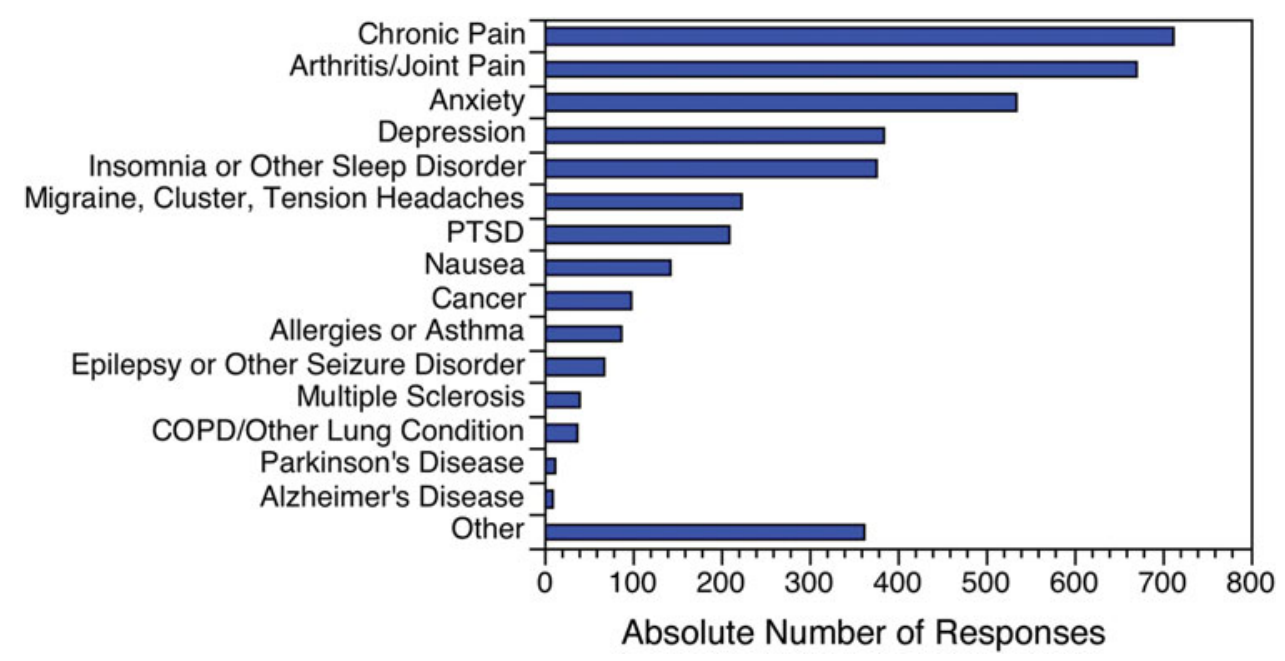

FIG. 1. Number of medical conditions for which respondents reported using $C B D$, by medical condition $(n=3963)$. CBD, cannabidiol; COPD, chronic obstructive pulmonary disease; PTSD, post-traumatic stress disorder. 


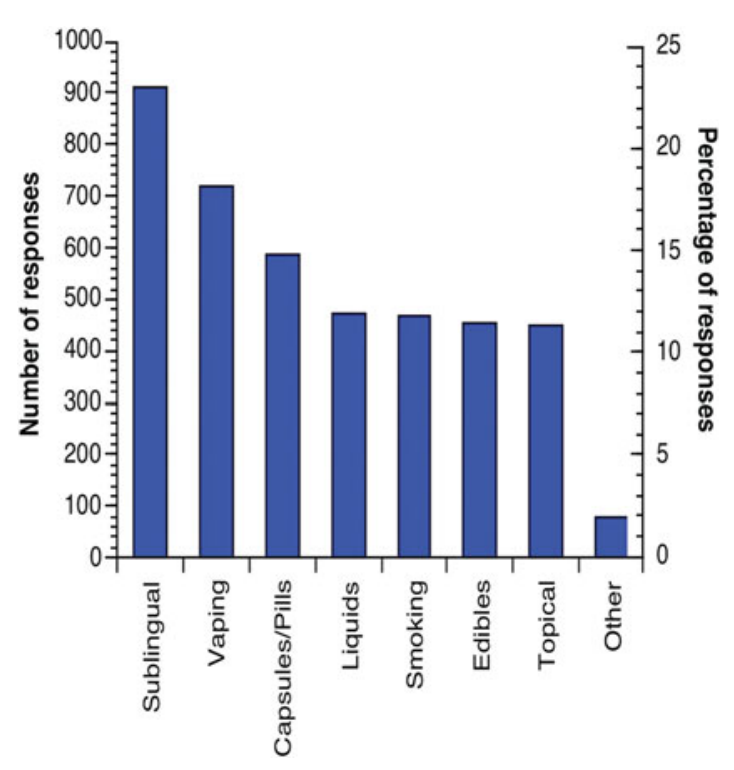

FIG. 2. Number and percentage of methods of administering CBD $(n=4135)$.

form (Fig. 2). This includes liquids administered as sprays, drops, and tinctures. The least common method was topical use.

More than half (51.36\%) of those reporting a method of administration reported using only one method $(n=$ 1130; missing $=209$; not including “Other," $n=31$ ). On average, respondents who reported using one method of administration were 1.6 times more likely to use CBD for a medical condition than for general health and well-being (medical condition, $n=691$; general health and well-being, $n=439)$. Medical users reporting one method of administration were 2.4 times more likely to use a topical form, 2.0 times more likely to use an edible form of CBD, and 1.8 times more likely to use CBD in a sublingual or pill or capsule form than general health and well-being users reporting one method.

Learning about $C B D$, frequency and duration of use Overall, $75.85 \%$ of respondents reported learning about CBD from internet research, family members, or friends. Of the remaining respondents, medical users were more likely to learn about CBD from a Medical Doctor or Naturopathic Doctor and to use it more frequently than those using it for general health and well-being. The odds of using CBD to treat a medical condition were 1.79 (95\% CI, 1.46-2.19) times greater among respondents using it more than once per day compared with those using it daily (Table 3 ). Duration of use was more variable, but the odds of using CBD to treat a medical condition were greater among those using it for $<5$ years (Table 3 ).

\section{Treatment efficacy}

Only respondents who reported using $\mathrm{CBD}$ to treat a medical condition were asked about its efficacy $(n=1483)$. Almost $36 \%(35.80 \%)$ of respondents reported that CBD treats their medical condition(s) "very well by itself," while only $4.30 \%$ reported "not very well" (Table 4). Respondents most frequently reported feeling that $\mathrm{CBD}$ treated their medical condition(s) "very well by itself" or "moderately well by itself" for the following three conditions: chronic pain, arthritis/joint pain, and anxiety (Fig. 3).

The odds of regular Cannabis use were two to three times greater among those who reported feeling that CBD treated their medical condition "very well by itself" (OR, 2.32; 95\% CI, 1.29-4.18) or "moderately well by itself” (OR, 2.92; 95\% CI, 1.61-5.29; see Table 4).

\section{Side effects}

A minimum of 1314 side effects were reported across 2409 respondents (missing, $n=1095$ ). Seven hundred eighty-five $(59.74 \%)$ of these effects were categorized as adverse (Table 5). On average, this represents at least one reported adverse effect in approximately one out of every three (3.07) users of CBD.

The top five most frequently reported adverse effects were dry mouth ( $n=268,11.12 \%$ of all CBD users), euphoria $(n=155,6.43 \%)$, hunger $(n=153,6.35 \%)$, red eyes $(n=66,2.74 \%)$, and sedation/fatigue $(n=43$, $1.78 \%)$. Just under $30 \%(28.46 \%)$ of medical users reported an adverse effect when compared with $34.56 \%$ of general health and well-being users.

\section{Discussion}

To our knowledge, this is the first published survey (aside from industry reports) that specifically analyzes CBD users, as opposed to overall Cannabis or medical Cannabis users. The results of this study suggest that CBD is used more frequently as a specific therapy for medical conditions than for general health and wellbeing. This stands in contrast to the majority of marijuana users, who largely use THC-dominant Cannabis for recreational or nonmedical reasons. ${ }^{38}$

The most common medical condition for which CBD was reportedly used was pain. In preclinical studies, CBD-based analgesia is associated with potent immune-modulatory, anti-inflammatory, and 
Table 3. Odds of Using Cannabidiol for a Medical Condition, by Cannabidiol Usage Characteristics $(n=2409)$

\begin{tabular}{|c|c|c|c|}
\hline & $\begin{array}{l}\text { General health and well-being, }(n=926) \\
n(\%)\end{array}$ & $\begin{array}{l}\text { Medical condition, }(n=1483) \\
n(\%)\end{array}$ & OR $(95 \% \mathrm{Cl})$ \\
\hline \multicolumn{4}{|l|}{ Learned about CBD** } \\
\hline Family member/friend & $320(41.24)$ & $456(58.76)$ & 1.00 (reference) \\
\hline Internet research & 337 (38.04) & $549(61.96)$ & $1.14(0.94-1.39)$ \\
\hline Physician/naturopathic doctor & $58(27.36)$ & $154(72.64)$ & $1.86(1.33-2.60)$ \\
\hline Other (please specify) & $131(41.32)$ & $186(58.68)$ & $1.00(0.76-1.30)$ \\
\hline Missing & 80 & 138 & \\
\hline \multicolumn{4}{|l|}{ Frequency of use $\mathrm{e}^{* * *}$} \\
\hline Daily & 418 (39.70) & $635(60.30)$ & 1.00 (reference) \\
\hline$<$ Once per day & $227(56.47)$ & 175 (43.53) & $0.51(0.40-0.64)$ \\
\hline > Once per day & $196(26.92)$ & $532(73.08)$ & $1.79(1.46-2.19)$ \\
\hline Missing & 85 & 141 & \\
\hline \multicolumn{4}{|l|}{ Duration of use (years)* } \\
\hline$>5$ & $134(53.17)$ & $118(46.83)$ & 1.00 (reference) \\
\hline $2-5$ & $151(35.61)$ & $273(64.39)$ & $2.05(1.50-2.82)$ \\
\hline $1-2$ & 202 (42.98) & $268(57.02)$ & $1.51(1.11-2.05)$ \\
\hline$<1$ & $364(34.57)$ & $689(65.43)$ & $2.15(1.63-2.84)$ \\
\hline Missing & 75 & 135 & \\
\hline
\end{tabular}

${ }^{*} p<0.05,{ }^{* *} p<0.01,{ }^{* * *} p<0.001$.

antioxidant activity. ${ }^{39-47} \mathrm{CBD}$ acts as an agonist for a wide variety of cell-surface receptors including adenosine $\mathrm{A} 2{ }_{\mathrm{A}}, 5-\mathrm{HT}_{1 \mathrm{~A}}, \mathrm{TRPV} 1, \alpha 7 \mathrm{nAch}, \alpha 3$ glycine receptors, and the peroxisome proliferator-activated receptor gamma (PPAR- $\gamma$ ) nuclear receptor. These receptors are all associated with anti-inflammatory activity. ${ }^{48-58}$ Consistent with the efficacy reported by survey respondents, CBD has been shown to reduce inflammatory cytokines in murine models of inflammatory disease and chronic and acute pain. ${ }^{59}$

The endocannabinoid system may also play a role in CBD-mediated analgesia. CBD inhibits enzymes (i.e., fatty acid amide hydrolase and monoacylglycerol lipase) that degrade endocannabinoids. This inhibition is associated with increased endocannabinoid levels, analgesia, and opioid-sparing effects in preclinical models of pain. ${ }^{60}$

Anxiety and depression were also commonly reported reasons for $\mathrm{CBD}$ use in this survey. $\mathrm{CBD}$ has long been proposed to inhibit THC-associated anxiety by antagonizing cannabinoid receptor activation by $\mathrm{THC}^{61-63}$
CBD may also reduce anxiety via the serotonin 5$\mathrm{HT}_{1 \mathrm{~A}}$ and/or $\mathrm{GABA}_{\mathrm{A}}$ receptors. ${ }^{14,64}$ These receptor pathways are being explored in hopes of novel therapeutic strategies for phobias, post-traumatic stress disorder, and drug abuse. ${ }^{65,66}$

The majority of survey respondents learned about CBD from internet research, family members, or friends. This was the case for both medical and general health and well-being users. Over $74 \%$ of respondents reported using CBD daily or more than daily. Sublingual delivery was the most common route of administration in both groups. The frequency of use of sublingual preparations found in this study contradicts a recent industry-funded CBD survey where respondents reported more frequent vaping, smoking, and topical use. ${ }^{67}$ This industry survey was collected from customers of an online medical marijuana recommendation service. Presumably, these respondents were seeking marijuana-derived products, so the frequency of inhalation as a method

Table 4. Number and Percentage of Respondents Using Cannabidiol for a Medical Condition, by Treatment Efficacy and Regular Cannabis Use

\begin{tabular}{|c|c|c|c|c|}
\hline $\begin{array}{l}\text { How well do you feel CBD treats } \\
\text { your medical condition(s)? }\end{array}$ & $(n=1483)$ & $\begin{array}{l}\text { Regular cannabis use }(n=674) \\
n(\%)\end{array}$ & $\begin{array}{l}\text { Nonregular cannabis use }(n=628) \\
n(\%)\end{array}$ & OR $(95 \% \mathrm{Cl})$ \\
\hline Not very well & $57(4.30)$ & $18(31.58)$ & $39(68.42)$ & 1.00 (reference) \\
\hline $\begin{array}{l}\text { Well in combination with } \\
\text { conventional medicine* }\end{array}$ & $404(30.44)$ & 195 (49.24) & $201(50.76)$ & $2.11(1.170-3.82)$ \\
\hline Moderately well by itself*** & $391(29.46)$ & $221(57.40)$ & $164(42.60)$ & $2.92(1.61-5.29)$ \\
\hline Very well by itself & $475(35.80)$ & $240(51.72)$ & $224(48.28)$ & $2.32(1.29-4.18)$ \\
\hline Missing** & 156 & 0 & 0 & 0 \\
\hline
\end{tabular}

${ }^{*} p<0.05,{ }^{* *} p<0.01,{ }^{* * *} p<0.001$. 


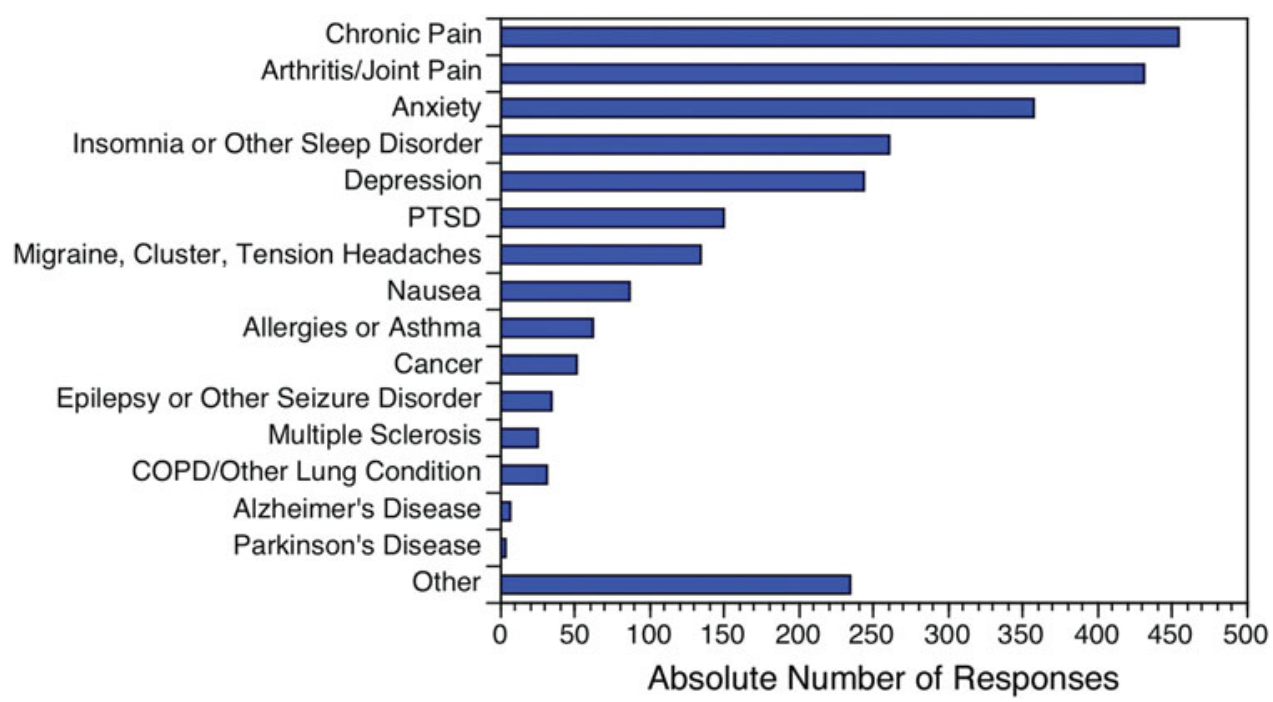

FIG. 3. Number of medical conditions for which respondents report CBD treating "Very Well by Itself" or "Moderately Well by Itself," by medical condition $(n=2557)$.

of administration is consistent with marijuana users overall. ${ }^{68}$ Our finding may be in part due to the fact that hemp-derived CBD products are largely distributed online and in health-food stores and widely offered as oral preparations.

The percentage of respondents (55.17\%) who reported regular Cannabis use is markedly higher than national estimates. In 2015, an estimated 8.3\% ( $\sim 22.2$ million people) of individuals aged 12 years or older had used marijuana in the past month. ${ }^{69}$ The reason for the higher rate of Cannabis use among survey respondents is not clear, although one possibility is that Cannabis users would be more likely to have heard of CBD. However, CBD use by a relatively high percentage (44.83\%) of nonregular Cannabis users suggests that individuals are not using $\mathrm{CBD}$ as a perceived legal route to THC consumption.
Approximately half of all respondents reported using $\mathrm{CBD}$ for $<1$ year. Just over $10 \%$ reported using CBD for $>5$ years. Nonserious adverse effects were relatively common among respondents and higher among those using CBD for general health and well-being, despite the fact that this group reported less frequent use than medical users. While dry mouth, sedation/fatigue, decreased appetite, and diarrhea have previously been reported following CBD use, ${ }^{6,7}$ other studies have demonstrated no adverse effects. ${ }^{10,70-72}$ This dichotomy may be related to dose, interactions with prescription medications, or both. More broadly, adverse effects may also be related to the method of administration and/or the use of purified, high-dose CBD as opposed to $\mathrm{CBD}$ in a whole plant extract. These questions and more reinforce the need for more research on unanticipated consequences of $\mathrm{CBD}$ use, particularly the

Table 5. Most Common Adverse Effects Reported by Survey Respondents $(n=742)$

\begin{tabular}{lccc}
\hline Adverse effect & $\begin{array}{c}\text { Medical condition }(\boldsymbol{n = 1 4 8 3 )} \\
\mathbf{n}(\%)\end{array}$ & $\begin{array}{c}\text { General health and well-being }(\boldsymbol{n}=\mathbf{9 2 6}) \\
\mathbf{n}(\%)\end{array}$ & $\begin{array}{c}\text { Total }(\boldsymbol{n}=\mathbf{2 4 0 9 )} \\
\mathbf{n}(\%)\end{array}$ \\
\hline Dry mouth & $174(11.73 \%)$ & $94(10.15 \%)$ & $268(11.12 \%)$ \\
Euphoria & $59(3.98 \%)$ & $96(10.37 \%)$ & $155(6.43 \%)$ \\
Hunger & $80(5.39 \%)$ & $73(7.88 \%)$ & $153(6.35 \%)$ \\
Other & $46(3.10 \%)$ & $11(1.19 \%)$ & $57(2.37 \%)$ \\
Red eyes & $34(2.29 \%)$ & $32(3.46 \%)$ & $66(2.74 \%)$ \\
Sleepy/groggy & $29(1.96 \%)$ & $14(1.51 \%)$ & $43(1.78 \%)$ \\
Total adverse effects & $422(28.46 \%)$ & $320(34.56 \%)$ & $742(30.80 \%)$ \\
\hline
\end{tabular}


impact of long-term usage. ${ }^{4,5}$ Many of the adverse effects reported in this study (i.e., euphoria, hunger, and red eyes) are commonly associated with THC use. $^{73}$ These analyses did not attempt to discriminate between hemp-derived CBD and marijuana-derived CBD products, which may have differing chemical constituents (including THC content) and therefore different effects. Further, no discrimination could be made between isolated CBD and CBD used as a constituent of a whole plant extract.

Industry-originated studies have found that users are confused about the source of their $\mathrm{CBD}$ and the concentration of $\mathrm{CBD}$ and other ingredients. ${ }^{67-74}$ It is worth noting that independent research has confirmed that the CBD content in almost $70 \%$ of CBD-labeled products available online may be mislabeled. In one study, $43 \%$ of products were underlabeled and $26 \%$ were overlabeled for actual CBD content. More than $20 \%$ contained detectable levels of THC. $^{75}$ Since CBDcontaining products are largely unregulated there is no obvious way for users to know the quantity of $\mathrm{CBD}$, or other constituents, which may be present in the products they use. Given this uncertainty, it is possible that some of the reported efficacy and the adverse effects may be in part due to the inclusion of other compounds in the CBD preparation, including THC.

\section{Strengths and limitations}

This study has several strengths, including the size, geographic representation of the sample, wide age range of the respondents, and a focus on specific usage characteristics. In part, this was the result of utilizing multiple recruitment methodologies.

In terms of limitations, the study population was a self-selected convenience sample, and as such, may not be representative of the general population or the overall population of $\mathrm{CBD}$ users. Individuals with favorable opinions of or experiences with $\mathrm{CBD}$ or Cannabis are more likely to have responded to the questionnaire than those with negative opinions and experiences. In addition, "regular cannabis use" was not defined in the survey and "marijuana" was not distinguished from "Cannabis." Since the survey was primarily circulated via the internet, $\mathrm{CBD}$ users with limited social media connectivity would be underrepresented. Finally, no mechanism for identifying repeat respondents was incorporated into the survey. Although results were examined manually, it is possible that repeat respondents may have distorted the results (i.e., Ballot stuffing).

\section{Conclusion}

The use of $\mathrm{CBD}$ among individuals for both specific health conditions and general health and well-being is widespread. The results of this study demonstrate that individuals are learning about CBD from the internet, friends, or family members, rather than from healthcare professionals. CBD is being used as a specific therapy for a number of diverse medical conditions-particularly pain and inflammatory disorders, in addition to anxiety, depression, and sleep disorders. A large percentage of respondents indicate that $\mathrm{CBD}$ treats their condition(s) effectively in the absence of conventional medicine and with nonserious adverse effects. These data provide a compelling rationale for further research to better understand the therapeutic potential of CBD in treating chronic pain, anxiety, depression, sleep disorders, and other medical conditions.

\section{Acknowledgments}

The authors thank Gina Spidel for help with survey design, proofreading, and assistance with the SDSU Electronic Internal Review Board; Edgar Herrera for setting up the survey Facebook page; Belle Della Cruz for help with survey wording; and Rod Kight, Esq., for assistance in clarifying the regulatory status of CBD in the United States.

\section{Author Disclosure Statement}

J.C. is the Medical Director at The Center for Medical Cannabis Education, a for-profit clinical, research and consulting entity.

\section{References}

1. Upton R, Craker L, ElSohly M, et al. Cannabis inflorescence (Cannabis spp.): standards of identity, analysis, and quality control. A Monograph Volume 66. American Herbal Pharmacopia: Scotts Valley, CA, 2014.

2. Adams RHM, Clark JH. Structure of cannabidiol, a product isolated from the marihuana extract of Minnesota wild hemp. J Am Chem Soc. 1940;62:196-200.

3. Mechoulam R, Shvo Y. Hashish. I. The structure of cannabidiol. Tetrahedron. 1963;19:2073-2078.

4. Iffland K, Grotenhermen F. An update on safety and side effects of cannabidiol: a review of clinical data and relevant animal studies. Cannabis Cannabinoid Res. 2017;2:139-154.

5. World Health Organization Expert Committee on Drug Dependence. Cannabidiol (CBD) Pre-Review Report Agenda Item 5.2 and Peer Review, 2017.

6. Devinsky O, Marsh E, Friedman D, et al. Cannabidiol in patients with treatment-resistant epilepsy: an open-label interventional trial. Lancet Neurol. 2016;15:270-278.

7. Devinsky O, Cross JH, Laux L, et al. Trial of cannabidiol for drug-resistant seizures in the Dravet syndrome. N Engl J Med. 2017;376:2011-2020.

8. Leweke FM, Piomelli D, Pahlisch F, et al. Cannabidiol enhances anandamide signaling and alleviates psychotic symptoms of schizophrenia. Transl Psychiatry. 2012;2:e94.

9. McGuire $\mathrm{P}$, Robson $\mathrm{P}$, Cubala WJ, et al. Cannabidiol (CBD) as an adjunctive therapy in schizophrenia: a multicenter randomized controlled trial. Am J Psychiatry. 2018;175:225-231. 
10. Zuardi AW, Shirakawa I, Finkelfarb E, et al. Action of cannabidiol on the anxiety and other effects produced by delta 9-THC in normal subjects. Psychopharmacology (Berl). 1982;76:245-250.

11. Bergamaschi MM, Queiroz RH, Zuardi AW, et al. Safety and side effects of cannabidiol, a Cannabis sativa constituent. Curr Drug Saf. 2011;6:237-249.

12. Bergamaschi MM, Queiroz RH, Chagas MH, et al. Cannabidiol reduces the anxiety induced by simulated public speaking in treatment-naive social phobia patients. Neuropsychopharmacology. 2011;36:1219-1226.

13. Crippa JA, Derenusson GN, Ferrari TB, et al. Neural basis of anxiolytic effects of cannabidiol (CBD) in generalized social anxiety disorder: a preliminary report. J Psychopharmacol. 2011;25:121-130.

14. de Mello Schier AR, de Oliveira Ribeiro NP, Coutinho DS, et al. Antidepressant-like and anxiolytic-like effects of cannabidiol: a chemical compound of Cannabis sativa. CNS Neurol Disord Drug Targets. 2014;13: 953-960.

15. Hayakawa K, Mishima K, Fujiwara M. Therapeutic potential of nonpsychotropic cannabidiol in ischemic stroke. Pharmaceuticals (Basel). 2010;3:2197-2212.

16. O'Connell BK, Gloss D, Devinsky O. Cannabinoids in treatment-resistant epilepsy: a review. Epilepsy Behav. 2017;70(Pt B):341-348.

17. Keating GM. Delta-9-tetrahydrocannabinol/cannabidiol oromucosal spray (Sativex((R))): a review in multiple sclerosis-related spasticity. Drugs. 2017, 77:563-574.

18. da Rovare VP, Magalhaes GPA, Jardini GDA, et al. Cannabinoids for spasticity due to multiple sclerosis or paraplegia: a systematic review and meta-analysis of randomized clinical trials. Complement Ther Med. 2017; 34:170-185.

19. Johnson JR, Burnell-Nugent $M$, Lossignol $D$, et al. Multicenter, doubleblind, randomized, placebo-controlled, parallel-group study of the efficacy, safety, and tolerability of THC:CBD extract and THC extract in patients with intractable cancer-related pain. J Pain Symptom Manage. 2010;39:167-179.

20. Whiting PF, Wolff RF, Deshpande S, et al. Cannabinoids for medical use: a systematic review and meta-analysis. JAMA. 2015;313:2456-2473.

21. GW Pharmaceuticals. GW Pharmaceuticals and Its U.S. Subsidiary Greenwich Biosciences Completes Rolling New Drug Application Submission to U.S. Food and Drug Administration for Epidiolex ${ }^{\circledR}$ (cannabidiol) in the treatment of Lennox-Gastaut syndrome and Dravet syndrome. 2017. Available at: www.gwpharm.com/about-us/news/ gw-pharmaceuticals-and-its-us-subsidiary-greenwich-biosciencescompletes-rolling-new (last accessed May 3, 2018).

22. GW Pharmaceuticals. Unanimous positive result of FDA Advisory Committee Meeting for first plant-based pharmaceutical cannabidiol treatment for seizures in patients with two rare, severe forms of epilepsy. 2018. Available at: www.gwpharm.com/about-us/news/gw-pharmaceuticalsannounces-unanimous-positive-result-fda-advisory-committee-meeting (last accessed May 3, 2018).

23. GW Pharmaceuticals plc and its U.S. Subsidiary Greenwich Biosciences Announce FDA Approval of EPIDIOLEX ${ }^{\circledR}$ (cannabidiol) oral solution - the First Plant-derived Cannabinoid Prescription Medicine | GW Pharmaceuticals [press release]. 2018.

24. Abuhasira R, Shbiro L, Landschaft Y. Medical use of cannabis and cannabinoids containing products-regulations in Europe and North America. Eur J Intern Med. 2018;49:2-6.

25. Bill C-45 | openparliament.ca. 2018; https://openparliament.ca/bills/42-1/ C- $-45 \%$.

26. A Tough Week for CBD: The HIA v. DEA Ruling and a Bad Wisconsin Policy | Kight on Cannabis. 2018; https://cannabusiness.law/a-tough-week-for-cbdthe-hia-v-dea-ruling-and-a-wisconsin-policy-underline-need-for-clarity/.

27. United States Drug Enforcement Agency. Denial of petition to initiate proceedings to reschedule marijuana. Fed Regist. 2016;81:53767-53845.

28. United States Drug Enforcement Agency. Establishment of a new drug code for marihuana extract. Fed Regist. 2016;81:90194-90196.

29. Hudak J, Stenglein C. DEA guidance is clear: cannabidiol is illegal and always has been. 2017. Available at: www.brookings.edu/blog/fixgov/ 2017/02/06/cannabidiol-illegal-and-always-has-been (last accessed May 3, 2018).

30. Kight R. Is CBD illegal under the new DEA "marihuana extract" rule? A legal analysis. Kight on Cannabis, 2018. Available at: https:// cannabusiness.law/is-cbd-illegal-under-the-new-dea-marihuana-extractrule-a-legal-analysis (last accessed May 3, 2018).
31. United States Congress. Agricultural Act of 2014. Public Law 79. U.S. Government Printing Office: Washington, DC, 2004.

32. United States Congress. Comprehensive Drug Abuse Prevention and Control Act of 1970. Public Law 513. U.S. Government Printing Office: Washington, DC, 1970.

33. Fletcher BB. On petition for review of an order of the drug enforcement agency. United States Court of Appeals for the Ninth Circuit. 2004; no. 0371366. San Francisco, CA.

34. United States Drug Enforcement Agency. Clarification of the New Drug Code 7350 for Marijuana Extract. United States Department of Justice, 2016. Available at: www.deadiversion.usdoj.gov/schedules/marijuana/ m_extract_7350.html (last accessed May 3, 2018).

35. Kight $R$. The legal status of cannabidol, other cannabinoids and terpenes derived from industrial hemp. Cannabis Law J. August 25, 2017.

36. United States Food and Drug Administration. FDA and marijuana: questions and answers. 2017. Available at: www.fda.gov/NewsEvents/ PublicHealthFocus/ucm421168htm (last accessed May 3, 2018).

37. Brightfield Group. Hemp CBD Report. 2018.

38. Pacula RL, Jacobson M, Maksabedian EJ. In the weeds: a baseline view of cannabis use among legalizing states and their neighbours. Addiction. 2016;111:973-980.

39. Coffey RG, Yamamoto Y, Snella E, et al. Tetrahydrocannabinol inhibition of macrophage nitric oxide production. Biochem Pharmacol. 1996;52:743-751.

40. Formukong EA, Evans AT, Evans FJ. Analgesic and antiinflammatory activity of constituents of Cannabis sativa L. Inflammation. 1988;12:361-371.

41. Watzl B, Scuderi $P$, Watson RR. Marijuana components stimulate human peripheral blood mononuclear cell secretion of interferon-gamma and suppress interleukin-1 alpha in vitro. Int J Immunopharmacol. 1991;13: 1091-1097.

42. Srivastava MD, Srivastava BI, Brouhard B. Delta9 tetrahydrocannabinol and cannabidiol alter cytokine production by human immune cells. Immunopharmacology. 1998;40:179-185.

43. Malfait AM, Gallily R, Sumariwalla PF, et al. The nonpsychoactive cannabis constituent cannabidiol is an oral anti-arthritic therapeutic in murine collagen-induced arthritis. Proc Natl Acad Sci U S A. 2000;97:9561-9566.

44. Costa B, Colleoni M, Conti $\mathrm{S}$, et al. Oral anti-inflammatory activity of cannabidiol, a non-psychoactive constituent of cannabis, in acute carrageenan-induced inflammation in the rat paw. Naunyn Schmiedebergs Arch Pharmacol. 2004;369:294-299.

45. Weiss $L$, Zeira $M$, Reich $S$, et al. Cannabidiol lowers incidence of diabetes in non-obese diabetic mice. Autoimmunity. 2006;39:143-151.

46. Weiss L, Zeira M, Reich $\mathrm{S}$, et al. Cannabidiol arrests onset of autoimmune diabetes in NOD mice. Neuropharmacology. 2008;54:244-249.

47. Kozela E, Lev N, Kaushansky N, et al. Cannabidiol inhibits pathogenic T cells, decreases spinal microglial activation and ameliorates multiple sclerosislike disease in C57BL/6 mice. Br J Pharmacol. 2011;163:1507-1519.

48. Trevethick MA, Mantell SJ, Stuart EF, et al. Treating lung inflammation with agonists of the adenosine A2A receptor: promises, problems and potential solutions. Br J Pharmacol. 2008;155:463-474.

49. Minguet $S$, Huber $M$, Rosenkranz $L$, et al. Adenosine and $c A M P$ are potent inhibitors of the NF-kappa B pathway downstream of immunoreceptors. Eur J Immunol. 2005;35:31-41.

50. Sands WA, Martin AF, Strong EW, et al. Specific inhibition of nuclear factor-kappaB-dependent inflammatory responses by cell type-specific mechanisms upon A2A adenosine receptor gene transfer. Mol Pharmacol. 2004:66:1147-1159.

51. Petrat F, Boengler K, Schulz R, et al. Glycine, a simple physiological compound protecting by yet puzzling mechanism(s) against ischaemiareperfusion injury: current knowledge. Br J Pharmacol. 2012;165:2059-2072.

52. Wheeler MD, Thurman RG. Production of superoxide and TNF-alpha from alveolar macrophages is blunted by glycine. Am J Physiol. 1999;277(5 Pt 1):L952-L959.

53. Wheeler M, Stachlewitz RF, Yamashina S, et al. Glycine-gated chloride channels in neutrophils attenuate calcium influx and superoxide production. FASEB J. 2000;14:476-484.

54. Fernandes ES, Liang L, Smillie SJ, et al. TRPV1 deletion enhances local inflammation and accelerates the onset of systemic inflammatory response syndrome. J Immunol. 2012;188:5741-5751.

55. Gururajan A, Taylor DA, Malone DT. Cannabidiol and clozapine reverse MK-801-induced deficits in social interaction and hyperactivity in Sprague-Dawley rats. J Psychopharmacol. 2012;26:1317-1332. 
56. Borovikova LV, Ivanova $S$, Zhang $M$, et al. Vagus nerve stimulation attenuates the systemic inflammatory response to endotoxin. Nature. 2000; 405:458-462.

57. Tracey KJ. Physiology and immunology of the cholinergic antiinflammatory pathway. J Clin Invest. 2007;117:289-296.

58. Freire-Garabal M, Nunez MJ, Balboa J, et al. Serotonin upregulates the activity of phagocytosis through 5-HT1A receptors. Br J Pharmacol. 2003; 139:457-463.

59. Burstein SH, Zurier RB. Cannabinoids, endocannabinoids, and related analogs in inflammation. AAPS J. 2009;11:109-119.

60. Wilkerson JL, Ghosh S, Mustafa M, et al. The endocannabinoid hydrolysis inhibitor SA-57: intrinsic antinociceptive effects, augmented morphineinduced antinociception, and attenuated heroin seeking behavior in mice. Neuropharmacology. 2017;114:156-167.

61. Karniol IG, Shirakawa I, Takahashi RN, et al. Effects of delta9tetrahydrocannabinol and cannabinol in man. Pharmacology. 1975;13: 502-512.

62. Hollister LE, Gillespie H. Interactions in man of delta-9-tetrahydrocannabinol. II. Cannabinol and cannabidiol. Clin Pharmacol Ther. 1975;18:80-83.

63. Dalton WS, Martz R, Lemberger L, et al. Influence of cannabidiol on delta9-tetrahydrocannabinol effects. Clin Pharmacol Ther. 1976;19:300-309.

64. Bakas T, van Nieuwenhuijzen PS, Devenish SO, et al. The direct actions of cannabidiol and 2-arachidonoyl glycerol at GABAA receptors. Pharmacol Res. 2017;119:358-370.

65. Lee JLC, Bertoglio LJ, Guimaraes FS, et al. Cannabidiol regulation of emotion and emotional memory processing: relevance for treating anxiety-related and substance abuse disorders. Br J Pharmacol. 2017;174: 3242-3256.

66. Jurkus R, Day HL, Guimaraes FS, et al. Cannabidiol regulation of learned fear: implications for treating anxiety-related disorders. Front Pharmacol. 2016;7:454.

67. Hello MD. Understanding cannabidiol/CBD, summary report. The Brightfield Group. 2017.

68. Sexton M, Cuttler C, Finnell JS, et al. A cross-sectional survey of medical cannabis users: patterns of use and perceived efficacy. Cannabis Cannabinoid Res. 2016;1:131-138.
69. Center for Behavioral Health Statistics and Quality. Results from the 2015 National Survey on Drug Use and Health. HHS Publication No. SMA 164984, NSDUH Series H-51. 2016.

70. Zuardi AW. Cannabidiol: from an inactive cannabinoid to a drug with wide spectrum of action. Rev Bras Psiquiatr. 2008;30:271-280.

71. Zuardi AW, Crippa JA, Hallak JE, et al. A critical review of the antipsychotic effects of cannabidiol: 30 years of a translational investigation. Curr Pharm Des. 2012;18:5131-5140.

72. Jadoon KA, Tan GD, O'Sullivan SE. A single dose of cannabidiol reduces blood pressure in healthy volunteers in a randomized crossover study. JC Insight. 2017;2:e93760.

73. Wang T, Collet JP, Shapiro S, et al. Adverse effects of medical cannabinoids: a systematic review. CMAJ. 2008;178:1669-1678.

74. Care by Design. CBD Patent Survey. 2015.

75. Bonn-Miller MO, Loflin MJE, Thomas BF, et al. Labeling accuracy of cannabidiol extracts sold online. JAMA. 2017;318:1708-1709.

Cite this article as: Corroon J, Phillips JA (2018) A cross-sectional study of cannabidiol users, Cannabis and Cannabinoid Research 3:1, 152-161, DOI: 10.1089/can.2018.0006

\section{Abbreviations Used}

$\mathrm{CBD}=$ cannabidio

$\mathrm{Cl}=$ confidence interval

$\mathrm{COPD}=$ chronic obstructive pulmonary disease

$\mathrm{FDA}=$ Food and Drug Administration

$\mathrm{GED}=$ General Educational Development

$\mathrm{IRB}=$ institutional review board

$\mathrm{OR}=$ odds ratio

PTSD $=$ post-traumatic stress disorder

$\mathrm{THC}=$ tetrahydrocannabino

\section{Publish in Cannabis and Cannabinoid Research}

Cannabis and

Cannabinoid

Research
- Immediate, unrestricted online access

- Rigorous peer review

- Compliance with open access mandates

- Authors retain copyright

- Highly indexed

- Targeted email marketing

liebertpub.com/can 